\title{
COMMENTARY
}

\section{On the origins of lactate during sepsis}

\author{
Sébastien Gibot*1,2 \\ See related research by Michaeli et al., http://ccforum.com/content/16/4/R139
}

\begin{abstract}
The origins of sepsis-induced hyperlactatemia are still imperfectly understood and probably multifactorial, resulting both from an increased production by various tissues through aerobic and anaerobic glycolysis, and from a decreased lactate clearance. In the previous issue of Critical Care, Michaeli and colleagues showed that lactate elevation during mild endotoxemia is due to an increased aerobic production that does not take place in the muscle; other tissues/cells may thus be important contributors.
\end{abstract}

Hyperlactatemia during septic shock is undoubtedly an alarm signal that alerts clinicians that something is wrong. More than their initial concentrations, the absence of a rapid decrease of lactate levels upon resuscitation associates with a bad outcome and protocols aiming to improve lactate clearance have proven beneficial. On the contrary, the origin of the sepsis-induced hyperlactatemia is still imperfectly understood. Is it a matter of decreased clearance? Increased production? If so, by which tissues/cells?

In the previous issue of Critical Care, Michaeli and colleagues tried to answer these questions [1]. They used a well-established model of endotoxemia in 14 fasting healthy volunteers to assess the effect of lipopolysaccharide (LPS) administration on lactate production and lactate clearance. Furthermore, with the aid of a microdialysis technique they investigated whether muscles could be lactate producers. The main findings of this study were that endotoxin increased resting energy expenditure and lactate net production that did not take place in muscles. By contrast, lactate clearance was unaffected by LPS administration. Although interesting, this model does not recapitulate the complex physiology

\footnotetext{
*Correspondence: s.gibot@chu-nancy.fr

'Service de Réanimation Médicale, Hôpital Central, 29 avenue du Maréchal de Lattre de Tassigny, 54035 Nancy Cedex, France

Full list of author information is available at the end of the article
}

of sepsis: in particular, the increase of lactate concentration observed upon LPS was modest $(<1.5 \mathrm{mmol} / \mathrm{l})$ and transient, as was the elevation of endogenous catecholamine (epinephrine and norepinephrine) levels. Moreover, the effect of hypotension, altered cardiac output, or administration of vasopressors on lactate metabolism cannot be investigated in the endotoxin model.

For years, the explanation for hyperlactatemia during shock, and especially sepsis, had been the existence of anaerobic glycolysis due to insufficient oxygen delivery. In their present study, Michaeli and colleagues clearly show that lactate elevation may increase without any oxygen delivery compromise. Indeed, this traditional view was first challenged by James and colleagues, who linked hyperlactatemia to epinephrine stimulation of the sarcolemmal $\mathrm{Na}^{+}-\mathrm{K}^{+}$-ATPase pump [2]. Epinephrine binds to $\beta_{2}$-adrenoreptors, leading to an increase of cAMP production that finally activates the $\mathrm{Na}^{+}-\mathrm{K}^{+}-$ ATPase. The pump's energy is fueled by the compartmentalized glycolytic pathway associated with the pump itself [3], therefore directly linking ATPase activity and lactate production.

In support of this response for skeletal muscle $\mathrm{Na}^{+}-\mathrm{K}^{+}-$ ATPase pump activation in lactate production, our group observed in septic shock patients that the muscle to plasma lactate gradient was persistently positive ( $2 \mathrm{mmol} / \mathrm{l})$, thus indicating lactate production by the muscle. Importantly, this production was inhibited by the $\mathrm{Na}^{+}-\mathrm{K}^{+}$-ATPase blocker ouabain [4]. It is also worth noting that this phenomenon may not be confined to sepsis but might also apply to other forms of shock, including low-output forms [5,6]. This mechanism may not occur during mild endotoxemia, however, and, as suggested by the authors [1], lactate is produced elsewhere.

Innate immune cell stimulation is followed by rapid changes in nutrient flux, necessary for their activation. Besides, activated macrophages control energy metabolism and insulin action. In a recent metabolomic study, Través and colleagues demonstrated that LPS increased glucose consumption and lactate production by macrophages through an ERK1/2-dependent mechanism [7]. These changes were accompanied by an increase in the 
glycolytic flux. This work, highlighting the cross-talk between signal transduction and macrophage metabolism upon LPS stimulation, may add credence to a role for immune cells in the genesis of hyperlactatemia.

Contrasting with Michaeli and colleagues' findings, a reduction of lactate clearance could participate in hyperlactatemia. In hemodynamically stable septic shock patients, Levraut and colleagues observed that this clearance was decreased to $473 \mathrm{ml} / \mathrm{kg} / \mathrm{hour}$ [8], while it remained unaltered at $858 \mathrm{ml} / \mathrm{kg} /$ hour in Michaeli and colleagues' study [1]. The severity of the insult may thus probably influence lactate clearance.

All of these data clearly support the view that hypoperfusion and hypoxia are probably not the principal causes of increased lactate production during shock.

Finally, to further complicate things, everyone has already cared for authenticated septic shock patients that never presented with hyperlactatemia. This has been further investigated by Hernandez and colleagues [9], who concluded that these patients may exhibit a distinctive physiological profile within the spectrum of septic shock. The existence of such an entity nevertheless remains to be confirmed.

Hyperlactatemia during shock is probably multifactorial, resulting both from an increased production by various tissues (muscles, macrophages, and so forth) through aerobic and anaerobic glycolysis, and from a decreased lactate clearance. Michaeli and colleagues show that lactate elevation during mild aggression is due to an increased aerobic production that does not take place in the muscle.

\section{Abbreviations}

LPS, lipopolysaccharide.

\section{Competing interests}

The author declares that he has no competing interests.

\section{Author details}

'Service de Réanimation Médicale, Hôpital Central, 29 avenue du Maréchal de Lattre de Tassigny, 54035 Nancy Cedex, France. 2INSERM U961, Equipe TREM

Université de Lorraine, Faculté de Médecine, Nancy F-54000, France.

Published: 10 September 2012

\section{References}

1. Michaeli B, Martinez A, Revelly JP, Cayeux MC, Chiolero RL, Tappy L, Berger MM: Effects of endotoxin on lactate metabolism in humans. Crit Care 2012, 16:R139.

2. James JH, Fang CH, Schrantz SJ, Hasselgren PO, Paul RJ, Fischer JE: Linkage of aerobic glycolysis to sodium-potassium transport in rat skeletal muscle. J Clin Invest 1996, 98:2388-2397.

3. James JH, Luchette FA, McCarter FD, Fischer JE: Lactate is an unreliable indicator of tissue hypoxia in injury or sepsis. Lancet 1999, 354:505-508.

4. Levy B, Gibot S, Franck P, Cravoisy A, Bollaert PE: Relation between muscle Na_K_ATPase activity and raised lactate concentrations in septic shock: a prospective study. Lancet 2005, 365:871-875.

5. McCarter FD, James JH, Luchette FA, Wang L, Friend LA, King J-K, Evans JM George MA, Fischer JE: Adrenergic blockade reduces skeletal muscle glycolysis and $\mathrm{Na}^{+}, \mathrm{K}^{+}$-ATPase activity during hemorrhage. J Surg Res 2001, 99:235-244.

6. Levy B, Desebbe A, Montemont C, Gibot S: Increased aerobic glycolysis through beta- 2 stimulation is a common mechanism involved in lactate formation during shock states. Shock 2008, 30:417-421

7. Través PG, Atauri PD, Marín S, Pimentel-Santillana M, Rodríguez-Prados JC, Marín de Mas I, Selivanov VA, Martín-Sanz P, Boscá L, Cascante M: Relevance of the MEK/ERK signaling pathway in the metabolism of activated macrophages: a metabolomic approach. J Immunol 2012, 188:1402-1410.

8. Levraut J, Ciebiera JP, Chave S, Rabary O, Jambou P, Carles M, Grimaud D: Mild hyperlactatemia in stable septic patients is due to impaired lactate clearance rather than overproduction. Am J Respir Crit Care Med 1998, 157:1021-1026.

9. Hernandez H, Bruhn A, Castro R, Pedreros C, Rovegno M, Kattan E, Veas E, Fuentealba A, Regueira T, Ruiz C, Ince C: Persistent sepsis-induced hypotension without hyperlactatemia: a distinct clinical and physiological profile within the spectrum of septic shock. Crit Care Res Practice 2012. [Epub ahead of print] doi: 10.1155/2012/536852

doi:10.1186/cc11472

Cite this article as: Gibot S: On the origins of lactate during sepsis. Critical Care 2012, 16:151. 